\title{
Association between placental vitamin D receptor expression and cord blood vitamin D level and its effect on the birth weight of newborns
}

\author{
Paulraj Sathish ${ }^{1}$, Sajeethakumari Raveendran ${ }^{2}$, Ramasamy Padma ${ }^{1}$, Doraisami \\ Balakrishnan $^{3}$, Muthulakshmi Muthusami
}

${ }^{1}$ Department of Medical Research, ${ }^{2}$ Department of Obstetrics and Gynaecology, ${ }^{3}$ Departments of ENT and Audiology, SRM Medical College Hospital and Research Centre, Kanchipuram-603203, Tamilnadu, India

Received: 27 July 2016

Accepted: 02 August 2016

*Correspondence:

Dr. P. Sathish,

E-mail: sathishrajbt@gmail.com

Copyright: () the author(s), publisher and licensee Medip Academy. This is an open-access article distributed under the terms of the Creative Commons Attribution Non-Commercial License, which permits unrestricted non-commercial use, distribution, and reproduction in any medium, provided the original work is properly cited.

\begin{abstract}
Background: Vitamin D deficiency during pregnancy affects fetal growth and development. The present study explored the association between vitamin D levels in cord blood and placental vitamin D receptor expression.

Methods: A total of 54 subjects with live-born singleton deliveries were included in SRM Medical College Hospital and Research Centre, Kattankulathur, India. Cord blood and placenta was obtained at the time of delivery.

Results: The mean newborn vitamin D level was $20.07 \mathrm{ng} / \mathrm{mL}$ (13-27.50). The mean of relative vitamin D receptor (VDR) expression was 1.45Ct (range 0.10-2.6). Mean comparison of cord serum 25(OH) D3 and VDR revealed significant at $\mathrm{p}<0.05$ by student's t-test. The newborn anthropometric measurement of head circumference $31.44 \pm 3.99$ $\mathrm{cm}$, Chest circumference $28.88 \pm 4.30 \mathrm{~cm}$, Body length $45.52 \pm 8.05 \mathrm{~cm}$, Birth weight $2660.61 \pm 353.27 \mathrm{~g}$ had significant association with mean VDR expression at $\mathrm{p}<0.05$ level by student t-test analysis. Further, Pearson correlation coefficient also revealed strong positive correlation of placental VDR and cord serum vitamin $\mathrm{D}(\mathrm{r}=0.853, \mathrm{p}<0.05)$.

Conclusions: The present study indicates that there was a high prevalence of vitamin D deficiency in the south Indian newborns and the study suggested that VDR had crucial role in maternal to fetal nutrient transfer mechanism. Vitamin D status in cord blood is associated with the birth weight of newborns. Hence, Vitamin D levels during gestation may affect fetal growth and development.
\end{abstract}

Keywords: Vitamin D, Fetal length, Birth weight, Gestational weeks, Vitamin D receptor

\section{INTRODUCTION}

Vitamin D constitutes a group of fat-soluble secosteroids with pleiotropic effects that extend far beyond the traditional role of calcium homeostasis and bone metabolism. The actions of vitamin D are mediated by its receptor, the vitamin D receptor (VDR). VDR expression is present in various cell types and organs demonstrating the multifactorial role vitamin D play in the regulation of basic cellular functions including proliferation, differentiation and in the modulation of innate and adaptive immune responses. ${ }^{1}$ Research has increasingly focused on the adaptive nature of the placenta and this organ's ability to respond to fetal and maternal nutrient status to support optimal fetal growth, especially in the context of suboptimal nutrient availability. ${ }^{1}$ The mechanisms by which placental proteins respond to maternal/fetal signals and regulate transplacental nutrient transfer remain an evolving area of research. Several studies have linked maternal vitamin $\mathrm{D}$ status, as measured by circulating $25(\mathrm{OH}) \mathrm{D}$, with placental function and fetal growth, pregnancy outcomes and offspring risk of chronic disease..$^{2-4}$

The mechanism by which vitamin D crosses the placenta is not yet clear. Recent literature reviews reported that the main mechanism is passive diffusion, as occurs with sex steroid hormones. ${ }^{5}$ The free serum $25(\mathrm{OH}) \mathrm{D}$ fraction may 
reflect the amount available for cells according to the free $25(\mathrm{OH}) \mathrm{D}$ would cross the cellular lipid bilayer because of its solubility in fat. The fetus is entirely dependent on the mother for its supply not only of calcium but also of 25hydroxyvitamin $\mathrm{D}$, which crosses the placenta. Placental vein $25(\mathrm{OH}) \mathrm{D}$ concentrations correlate significantly with those found in the maternal circulation, implying that it diffuses easily across the placental barrier and that the vitamin D pool of the fetus depends entirely on that of the mother. ${ }^{6}$ Therefore, the present study was conducted to ascertain association of vitamin D receptor (VDR) expression and cord vitamin D level.

\section{METHODS}

This cross-sectional, hospital based study was conducted at the Obstetrics and Gynaecology Department of SRM Medical College Hospital and Research Centre, Kanchipuram (tertiary care centre predominantly catering to the needs of the poorer population of Tamil Nadu), India. A total of 54 consecutive singleton pregnant women admitted in labor were included. Twin or multiple pregnancies, congenital anomalies in the newborn and liver and kidney disorder subjects were excluded from the study. Informed consent was obtained from each study subject after the nature of the study was fully explained. The Institutional ethical clearance was obtained to conduct the study (No: 502/IEC/2013).

Maternal characteristics such as age, height, weight, parity and obstetrical history (gestational weeks, term of delivery) were recorded in a standardised questionnaire. Placental tissue samples were excised at random from central cotyledons after removal of any attached deciduas and placental infarcts and processed within 20 minutes of delivery. The placental tissues were divided into small portions and snap frozen in RNA later (Qiagen, USA) until analysis. Vitamin D receptor expression analysis done by real time PCR followed by Vural protocol. ${ }^{7}$

Cord blood was obtained at the time of delivery and serum separated for estimation of vitamin D. Newborn anthropometric measurements birth weight, height, head and neck circumference were measured at birth.

\section{Procedure}

\section{Estimation of $25(\mathrm{OH}) \mathrm{D} 3$ procedure}

Circulating 25(OH)D was measured as 25 hydroxyvitamin D3 (25(OH)D3) by HPLC in serum using a kit marketed by Chromosorb (Germany). Briefly, to $0.5 \mathrm{~mL}$ of serum are added $350 \mu \mathrm{L}$ of methanol-2propanol ( $80: 20$ by volume) and the $25(\mathrm{OH}) \mathrm{D}$ extracted by mixing three times with $2 \mathrm{~mL}$ of hexane. The phases were separated by centrifugation, and the upper organic phases combined and dried under nitrogen. The residue was then dissolved in $100 \mu \mathrm{L}$ of mobile phase. Calibration curves were constructed using four concentrations of $25(\mathrm{OH}) \mathrm{D}(15-120 \mathrm{nmol} / \mathrm{L})$ and human serum albumin $(50 \mathrm{~g} / \mathrm{L})$. For the chromatography we used a waters millenium HPLC (Waters Inc, Milford MA) fitted with a Li Chrospher $60 \mathrm{RP}$ select B column $(4 \times 250$ $\mathrm{mm} ; 5 \mu \mathrm{m}$ bead size; EMD, Bridgewater, $\mathrm{NJ}$ ) maintained at $40{ }^{\circ} \mathrm{C}$. The separation was achieved using $760 \mathrm{~mL} / \mathrm{L}$ methanol in water as the mobile phase with a flow rate of $1 \mathrm{~mL} / \mathrm{min}$ and detection at $265 \mathrm{~nm}$. The injected volume was $50 \mu \mathrm{L}$. The $25(\mathrm{OH}) \mathrm{D} 3$ and $25(\mathrm{OH}) \mathrm{D} 2$ peaks are completely resolved with retention times of 20.8-21.1 min and $23.1 \mathrm{~min}$, respectively. The within-assay and between assay CVs were $<8 \%$. Serum $25(\mathrm{OH})$ D3 was analysed by high performance liquid chromatography, according to the protocol of Turpeinen et al. ${ }^{8}$

The cut offs utilised to define vitamin D deficiency was based on institute of medicine. Subjects were grouped into different categories, based on the serum level of $25(\mathrm{OH}) \mathrm{D} 3$ as per the guidelines of Institute of Medicine (IOM). The IOM defines 25(OH)D3 serum level of $<10$ $\mathrm{ng} / \mathrm{mL}$ as severe deficiency, $<20 \mathrm{ng} / \mathrm{ml}$ as deficiency, 2030 as insufficiency and $>30 \mathrm{ng} / \mathrm{mL}$ as sufficiency. 9

\section{RNA extraction, cDNA synthesis, and real-time PCR}

Total RNA from placental tissues was extracted using the Rneasy Mini-kit (Qiagen, Limburg, Netherlands) as per protocol instructed. RNA yield, purity and integrity were determined using the NanoDrop 2000 spectrophotometer (Thermo Fisher Scientific, MA, USA). Total RNA (2 $\mu \mathrm{g})$ was reverse transcribed with cDNA conversion kit according to manufacturer's instructions (Qiagen, USA). Primers were designed from the VDR NCBI sequence for mRNA (forward primer 5'ACATCGGCATGATGAAGGA-3', reverse primer 5'TTCCGCTTCAGGATCATCTC-3') and control gene $\beta$ actin (forward primer 5'TTCTACAATGAGCTGCGTGTG-3', reverse primer 5'GGGGTGTTGAAGGTCTCAAA-3'). Quantitative realtime PCR for VDR expression was done using specific primer pair and SYBR green dye (Qiagen, USA). PCR conditions included an activation step of $95^{\circ} \mathrm{C}$ for 10 minutes, followed by 40 cycles of $95^{\circ} \mathrm{C}$ for 15 minutes and $60^{\circ} \mathrm{C}$ for 1 minute. $\beta$-actin mRNAs were also quantities and used as internal control for realtime PCR. $\mathrm{Ct}$ values for VDR were determined and VDR expressions normalized to $\beta$-actin were compared. All the experiments were done in triplicate and the average values were presented.

\section{Statistical analysis}

Statistical analysis was carried out using the SPSS statistical software package version 16. Data were expressed as means with their standard deviation and number of subjects in percentages. Comparisons were conducted using student's two-tailed t test. The Pearson correlation statistic was used to investigate correlations between variables. All statistical significance set for $\mathrm{p}<0.05$. 


\section{RESULTS}

The mean newborn vitamin D level was $20.07 \mathrm{ng} / \mathrm{mL}$ (13-27.50). Figure 1 showed the distribution of new born vitamin D level. Of 54 newborn, severe deficiency was noted sufficiency in $2(3.7 \%)$, deficiency in $29(53.7 \%)$, insufficiency in $13(24.07 \%)$ and sufficiency in 10 $(18.53 \%)$ of the newborn subjects. Totally, severe deficiency and deficiency together was 31 (57.4\%).

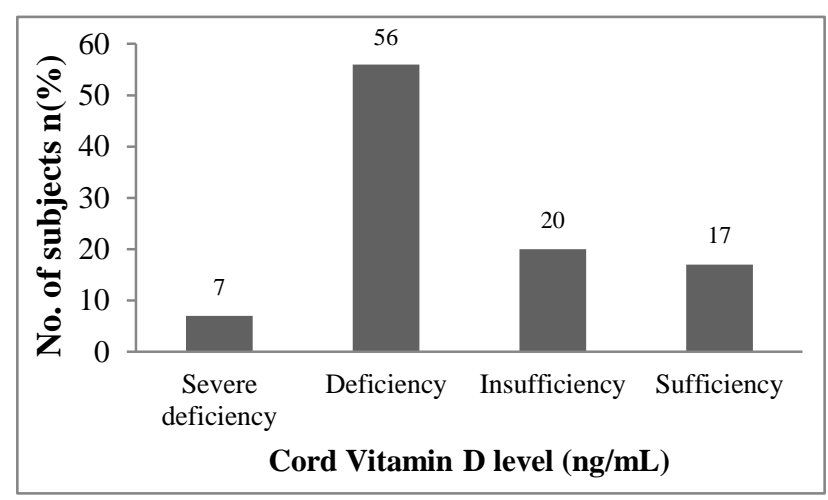

Figure 1: Distribution of newborn serum 25(OH)D3 level in the study subjects $(\mathrm{N}=54)$.

The mean of relative vitamin $\mathrm{D}$ receptor (VDR) expression was $20.07 \mathrm{Ct}$ (range 0.10-2.6). Figure 2 revealed significant association of placental VDR expression with cord serum vitamin D level by student's t-test at $\mathrm{p}<0.05$. Table 1 shows the comparative analysis of mean $\pm \mathrm{SD}$ of newborn characteristics with placental VDR expression level. The newborn anthropometric measurement of head circumference $31.44 \pm 3.99 \mathrm{~cm}$, chest circumference $28.88 \pm 4.30 \mathrm{~cm}$, body length $45.52 \pm 8.05 \mathrm{~cm}$, birth weight $2660.61 \pm 353.27 \mathrm{~g}$ had significant association with mean VDR expression at $p$ $<0.05$ level by student t-test analysis. Further, pearson correlation coefficient also revealed strong positive correlation of placental VDR and cord serum vitamin D $(\mathrm{r}=0.853, \mathrm{p}<0.05)$.

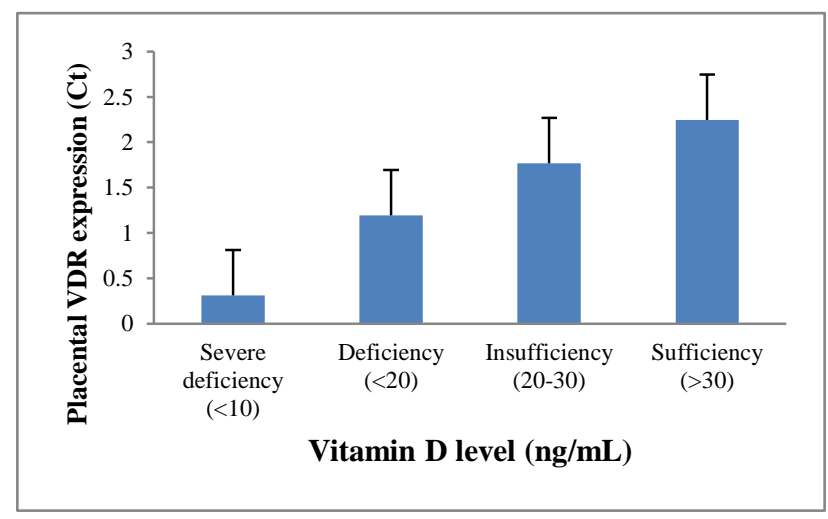

Figure 2: Association of cord serum 25(OH)D3 level and placental VDR expression.

The present study revealed that placental VDR had significant role in maternal to fetal nutrient transfer mechanism and thereby in newborn anthropometric measurements.

Table 1: Newborn clinical characteristics association with placental VDR expression.

\begin{tabular}{|c|c|c|}
\hline Characteristics & Mean \pm SD & P-value \\
\hline Head circumference & $31.44 \pm 3.99$ & \multirow{4}{*}{$0.021 *$} \\
\hline Chest circumference & $28.88 \pm 4.30$ & \\
\hline Body length & $45.52 \pm 8.05$ & \\
\hline Birth weight & $2660.61 \pm 353.27$ & \\
\hline
\end{tabular}

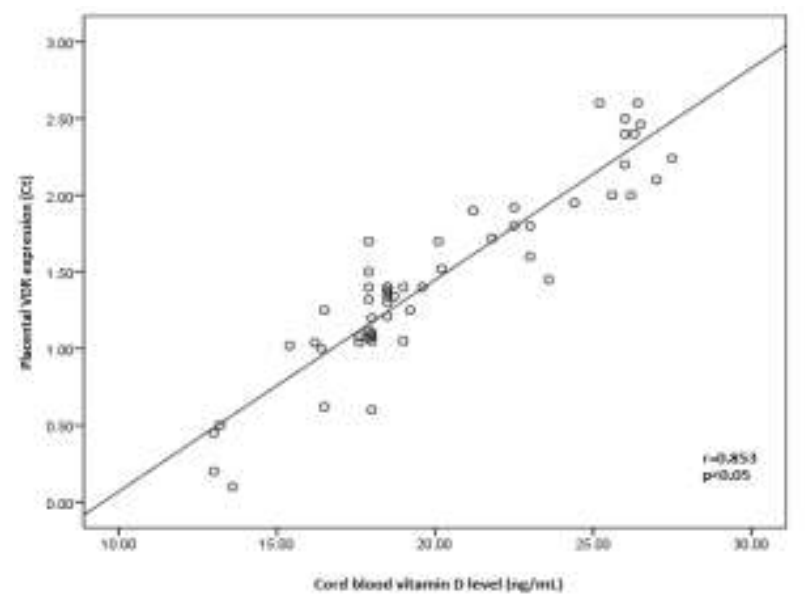

Figure 3: Correlation of cord serum 25(OH)D3 and placental VDR expression.

\section{DISCUSSION}

In India, vitamin D deficiency was considered to be rare. Till the year 2000, there was no systematic study which directly assessed body vitamin D status of Asian Indians residing in India. In 2000, Goswami measured serum $25(\mathrm{OH}) \mathrm{D}$ using sensitive and specific assay in apparently healthy subjects in Delhi and showed that significant hypovitaminosis D was present in up to 90 per cent of them.10 Subsequently, series of studies from different parts of our country have pointed towards widespread vitamin D deficiency in Asian Indians of all age groups including toddlers, school children, pregnant women and their neonates and adult males and females residing in rural or urban areas.11-13 The present study shows $57.4 \%$ prevalence of vitamin D deficiency in newborn.

VDR is an essential component of the vitamin D metabolic pathway where activation regulates and initiates the expression of numerous genes involved in cell proliferation and differentiation. The findings from this study showed that, VDR was expressed in the placenta indicating the eminent role of this vitamin D3 in the process of reproduction and fetal transfer mechanism. Therefore, decreased VDR expression may impair the actions and limit the beneficial effects of vitamin $\mathrm{D}$ in the regulation of feto-placental growth. Nguyen study reported that changes in VDR expression in idiopathic 
fetal growth restriction (FGR) were either a cause or a consequence of the pathophysiological defects observed in the FGR-affected placenta. ${ }^{14}$ Furthermore, Shahbazi study mention that the rationale behind placental VDR expression was unclear, but it had a role in the physiological processes such as absorption of calcium and its transition to the developing fetus before delivery. ${ }^{15}$

Newborn size had important implications for mortality, morbidity, subsequent growth and development. There were overwhelmingly more cases of LBW in developing countries than in developed countries. ${ }^{16}$ It is also a reflection of prenatal growth and the intra-uterine environment. Birth weight, especially low birth weight was known to be correlated with gestational age at birth.

Merialdi et al reported in their study, the effect of gestational age on size at birth was obvious, and in particular, birth weight was more affected by gestational age than birth length. ${ }^{17}$ However, the present study revealed the association of placental VDR expression with birth weight and length.

A study in 2012 reviewed all clinical studies published in the previous 15 years regarding vitamin D deficiency in pregnancy and its effects on their offspring and the vitamin D supplementation during pregnancy. It revealed that several studies have demonstrated the association of $25(\mathrm{OH}) \mathrm{D}$ deficiency with important health outcomes in the preconception period, during pregnancy, in perinatal period and in childhood. It suggested that $25(\mathrm{OH}) \mathrm{D}$ concentration of $>32$ and $<50-60 \mathrm{ng} / \mathrm{mL}$ may be associated with the lowest risk of disease. ${ }^{18}$

In conclusion, there was a high prevalence of vitamin D deficiency in the south Indian newborns and the study suggested that VDR had crucial role in maternal to fetal nutrient transfer mechanism. Hence, the study warrants supplementation of Vitamin D and evaluation of VDR expression.

\section{ACKNOWLEDGEMENTS}

The authors acknowledge helping rendered by Dr. Tarun, Ms. Kanaka of Obstetrics and gynaecology department for cord blood and maternal blood sample collection and also the subjects, who readily agreed to participate in this study. We thank the Dean Medical and the Honourable Pro Vice Chancellor Medical for their permission and encouragement.

Funding: No funding sources Conflict of interest: None declared

Ethical approval: The study was approved by the Institutional Ethics Committee

\section{REFERENCES}

1. Jansson T, Powell TL. Human placental transport in altered fetal growth: does the placenta function as a nutrient sensor? a review. Placenta. 2006;27:91-7.

2. Lewis S, Lucas RM, Halliday J, Ponsonby AL. Vitamin D deficiency and pregnancy: from preconception to birth. Mol Nutr Food Res. 2010;54:1092-102.

3. Wagner CL, Taylor SN, Dawodu A, Johnson DD, Hollis BW. Vitamin D and its role during pregnancy in attaining optimal health of mother and fetus. Nutr. 2012;4:208-30.

4. Brannon PM, Picciano MF. Vitamin D in pregnancy and lactation in humans. Annu Rev Nutr. 2011;31:89-115.

5. Lapillonne A. Vitamin D deficiency during pregnancy may impair maternal and fetal outcomes. Med Hypotheses. 2010;74(1):71-5.

6. Malhotra N, Mithal A, Gupta S, Godbole M. Effect of vitamin D supplementation on bone health parameters of healthy young Indian women. Osteoporos Int. 2008;19:29-32.

7. Vural HC, Maltas E. RT-qPCR assay on the vitamin $\mathrm{D}$ receptor gene in type 2 diabetes and hypertension patients in Turkey. Genet Mol Res 2012;11(1):58290.

8. Turpeinen U, Hohenthal U, Stenman U. Determination of 25-hydroxyvitamin D in serum by HPLC and immunoassay. Clin Chem. 2003;49:15214.

9. Ross AC, Taylor CL, Yaktine AL, Del VHB. Dietary reference intakes for calcium and vitamin $\mathrm{D}$. Washington, DC: committee to review dietary reference intakes for vitamin D and calcium. Institute of Medicine. 2011.

10. Goswami R, Gupta N, Goswami D. Prevalence and significance of low 25-hydroxyvitamin D concentrations in healthy subjects in Delhi. Am J Clin Nutr. 2000;72:472-5.

11. Arya V, Bhambri R, Godbole MM, Mithal A. Vitamin D status and its relationship with bone mineral density in healthy Asian Indians. Osteoporos Int. 2004;15(1):56-61.

12. Sachan A, Gupta R, Das V, Agarwal A, Awasthi PK, Bhatia V. High prevalence of vitamin D deficiency among pregnant women and their newborns in northern India. Am J Clin Nutr. 2005;81(5):1060-4.

13. Harinarayan CV, Ramalakshmi T, Prasad UV. High prevalence of low dietary calcium, high phytate consumption and vitamin D deficiency in healthy south Indians. Am J Clin Nutr. 2007;85:1062-7.

14. Nguyen TPH, Young HEJ, Chollangi T, Borg AJ, Brennecke SP, Murthi P. Placental vitamin D receptor expression is decreased in human idiopathic fetal growth restriction. J Mol Med. 2015;93:795-05.

15. Shahbazi M, Jeddi TM, Zareie M, Salek MA, Akhondi MM, Bahmanpoor M, Sadeghi MR, Zarnani AH. Expression profiling of vitamin D 
receptor in placenta, decidua and ovary of pregnant mice. Placenta. 2011;32:657-4.

16. Huang JY, Qiu C, Miller RS, Siscovick DS, Williams MA, Enquobahrie DA. Maternal birthweight is associated with subsequent risk of vitamin D deficiency in early pregnancy. Paediatr Perinat Epidemiol. 2013;27(5):472-80.
17. Merialdi M, Carroli G, Villar J. Nutritional interventions during pregnancy for the prevention or treatment of impaired fetal growth: an overview of randomized controlled trials. J Nutr. 2003;133:162631.

18. Holick MF. High prevalence of vitamin D inadequacy and implications for health. Mayo Clinic Proceedings. 2006;81(3):353-73.

Cite this article as: Sathish $\mathrm{P}$, Raveendran S, Padma $\mathrm{R}$, Balakrishnan D, Muthusami M. Association between placental vitamin $\mathrm{D}$ receptor expression and cord blood vitamin D level and its effect on the birth weight of newborns. Int J Reprod Contracept Obstet Gynecol 2016;5:2904-8. 